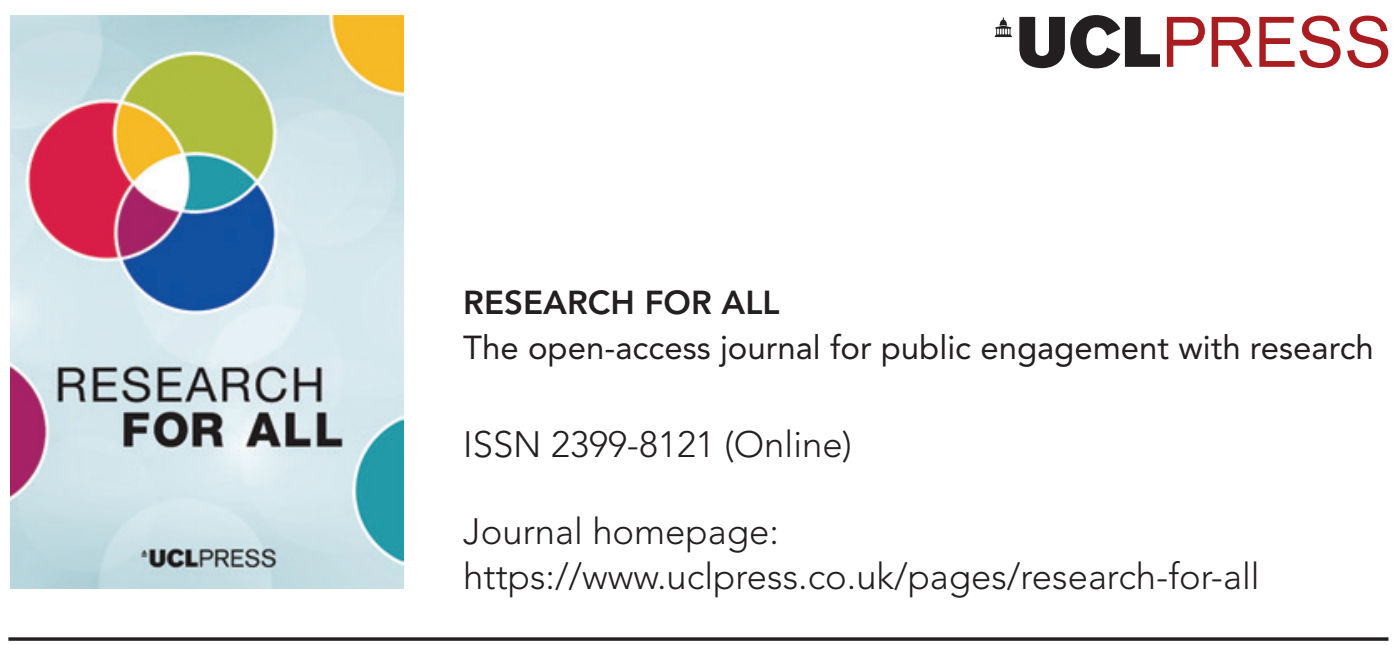

\title{
Knowledge exchange in the arts and humanities as creative economy policy assemblage
}

\section{Simon Moreton}

\section{How to cite this article}

Moreton, S. (2021) 'Knowledge exchange in the arts and humanities as creative economy policy assemblage'. Research for All, 5 (2), 271-89. https://doi.org/10.14324/ RFA.05.2.06

Submission date: 14 September 2020

Acceptance date: 29 April 2021

Publication date: 21 September 2021

\section{Peer review}

This article has been peer-reviewed through the journal's standard double-blind peer review, where both the reviewers and authors are anonymized during review.

\section{Copyright}

(C) 2021 Moreton. This is an open-access article distributed under the terms of the Creative Commons Attribution Licence (CC BY) 4.0 https://creativecommons.org/licenses/by/4.0/, which permits unrestricted use, distribution and reproduction in any medium, provided the original author and source are credited.

\section{Open access}

Research for All is a peer-reviewed open-access journal. 


\title{
Knowledge exchange in the arts and humanities as creative economy policy assemblage
}

\author{
Simon Moreton* - University of the West of England, Bristol, UK
}

\begin{abstract}
The creative economy is a complex assemblage of policy, practice and industrial activity, underpinned by apparently novel configurations of cultural and creative work. In recent years, it has become the focus of a number of schemes which have seen major shifts in how UK research councils fund universities. This paper reflects on the work of Research and Enterprise in Arts and Creative Technology (REACT), a major knowledge exchange programme aimed at stimulating growth in the creative sector through collaborations with universities in South West England and South Wales. In the first section, I unpack some of the underpinning logics of the 'creative turn' by which creativity has become a key currency in modern economies. I then consider how this shift has affected universities. I next ask how the various rationalities of an economy driven by creativity have moved into the knowledge exchange sphere. I approach this by formulating creative economy policy as a form of governmentality performed through assemblages that facilitate policy transfer. The paper turns to the empirical example of REACT, considering it as an assemblage through which reconfigurations of discourses, spatialities, temporalities, subjects and calculative practices have unfolded. The analysis shows how the multivalent, ad hoc and sometimes contradictory experience of producing an assemblage such as REACT means that policy transfer is never entirely complete nor stable, and that in this sense it is still possible for knowledge exchange programmes to imagine and generate alternative approaches to creativity that are not wholly reducible to a neoliberal or capitalist logic, although they remain implicated therein.
\end{abstract}

Keywords: creative economy, knowledge exchange, assemblage, governmentality, policy transfer

\section{Key messages}

- Knowledge exchange is a political construct and is not a natural effect of collaboration; as such, attention needs to be paid to how it is managed and run.

- Knowledge exchange with the creative economy is situated within a long-standing set of tensions around the nature of the creative economy, and particularly the role of the sector in national economic growth. This means that often knowledge exchange projects in this space are influenced by instrumental politics and metrics that are often at odds with more egalitarian ambitions for collaboration.

- These projects do offer opportunities to support more equitable, creative, culturally led, impactful collaborative work in the sector, but this process involves a balance of complicity and resistance to those politics in order to succeed. 


\section{Introduction}

The emergence of 'creativity' as a central driver in Western societies over the last thirty years has been a complicated and multivalent process. It has happened in part as a consequence of specific policies aimed at reclassifying industrial activities, but also through the production of a broader socio-economic imaginary that encompasses (but is not limited to) logics of placemaking and urban redevelopment led by cultural activities, industrial strategies driven by knowledge and innovation, the co-option of often transgressive cultural practices into the cultural and economic mainstream, the elision of social and economic policy, and the rise of 'creative' lifestyles and subjectivities, all under the auspices of a belief that creativity can solve both social and economic crises simultaneously (Mould, 2018).

British universities have been affected by this imaginary. Between 2012 and 2016, the Arts and Humanities Research Council (AHRC) invested $f 19.2$ million in regional university consortia to deliver a major knowledge exchange programme in the arts and humanities. The AHRC (2011a: 1) defined knowledge exchange as:

the processes by which new knowledge is co-produced through interactions between academic and non-academic individuals and communities. This includes innovative activity brought about by the application of existing knowledge to new contexts. The AHRC's interpretation of knowledge exchange assumes that the new knowledge that is created through such engagements results in significant added value for both the academic and non-academic partners.

The new knowledge exchange programme was designed to allow universities to fund collaborative work between micro- and medium-sized enterprises in the creative industries and arts and humanities disciplines. The programme emerged from the 2010 Comprehensive Spending Review undertaken by the UK Treasury during the formation of a new coalition government. In response to the Comprehensive Spending Review, the AHRC explicitly chose to lobby, via Research Councils UK (RCUK, now UK Research and Innovation (UKRI)), for funding to support relationships between the creative economy and higher education institutions (HEls), placing innovation activities as the core economic and social return that universities could offer on public investment (Moreton, 2016). The programme centred on four Knowledge Exchange Hubs for the Creative Economy: Research and Enterprise in Arts and Creative Technology (REACT), in Bristol; Creative Works, in London; Creative Exchange, in Lancaster; and Design in Action (DIA), in Dundee. Each was granted around $£ 4.4$ million. An additional ten 12-month grants were made to smaller consortia, along with a cross-research council initiative based in Glasgow called CREATe, which focused on intellectual property (IP) challenges in the creative sector.

The AHRC's investment in the Hubs programme was notable for two reasons. First, it was the first time the AHRC had devolved decision making about awarding its knowledge exchange funding to external organizations, and, second, it was specifically aimed at using arts and humanities disciplines to provide a 'flexible means for supporting innovative research-based knowledge exchange tailored to the research and skills needs of the Creative Economy' (AHRC, 2011b: 1).

Comunian and Gilmore (2016: 5) identify the increasing prevalence of these kinds of relationship between the creative and cultural sector and HEls as a new academic and policy phenomenon. In this paper, I consider their description of an emergent logic to these changes that posits 'creative knowledge and R\&D [research and development] as being fundamental to the development of an innovative and 
competitive creative economy' (Comunian and Gilmore, 2016: 6). Specifically, I seek to understand how the often problematic logics of contemporary creativity have found their way into the university via large-scale knowledge exchange projects.

This paper offers a case study of REACT to explore how it was implicated in the reproduction and renegotiation of normative creative economic ideologies. In the next section, I consider the 'creative turn' as a form of governmentality that has affected universities in four key ways, most notably the move towards a 'third mission' which seeks to commercialize university research (Shore and McLauchlan, 2012; Wright and Shore, 2017). I next consider assemblage and policy mobility literatures as a framework to understand the mechanisms by which the discourse of creativity travels. I then discuss REACT and its work, an analysis informed by my experience as the sole Research Fellow for REACT, during which I had a number of responsibilities that extended from evaluation and research into the programme itself, to operational duties supporting both the delivery of the programme and, alongside colleagues, the community of funding recipients that we brought together. This reflection is further informed by the analysis of over one hundred and fifty interviews with academics, administrators and practitioners involved in collaborative REACT projects, many hours spent on boards at all levels of project management, and participant observation at events, alongside bid-writing, project promotion, event planning and policy advocacy. The analysis expands on an approach I have outlined previously (Moreton, 2018) to decompose the processes associated with the delivery of REACT into five loose dimensions of creative economy-university assemblage - discourses, spaces, time, subjects and calculation.

\section{Ubiquitous creativity?}

\section{Creativity and knowledge as commodity in the university}

The UK Labour Government's creative industries programme (DCMS, 2008, 2001, 1998; Work Foundation, 2007) is widely understood as a milestone in the development of creative economy policy (Garnham, 2005; Oakley, 2011, 2006, 2004; Pratt, 2005). First announced in 1998, and refined in subsequent years, the policy recast a whole portion of the UK's workforce in a new light, with a message of 'entrepreneurs "in" and workers "out"' (Oakley, 2006: 260). The definition of the creative industries by the Department for Digital, Culture, Media and Sport (DCMS) notably only refers to 'industries which have their origin in individual creativity, skill and talent and which have a potential for wealth and job creation through the generation and exploitation of intellectual property' (DCMS, 2001: 4). This sleight of hand allowed policymakers and stakeholders to focus their concerns upon 'creativity' and its supposed capacity to generate social and economic change, without having to grapple with what the term meant. It saw creativity as both input and output of economic practice (Miller, 2009), made tangible in the form of IP and cultural commodities.

This shift towards a ubiquitous economic creativity has roots in the idea of knowledge-based economies. Drawing their origins from a variety of related ideologies on the changing nature of post-industrial society (Bell, 1973; Hayek, 1945), knowledge-based economies are understood as 'economies which are directly based on the production, distribution and use of knowledge and information' (OECD, 1996: 7) as new forms of commodity. One outcome of this move to commodify knowledge was that it required new forms of management to secure knowledge in the workplace and in workers - what Thrift (2006: 282) describes as 'a general exteriorization of intelligence out from the corporation' - and their capacity 
to ideate (Grant, 1996; Haner, 2005; Jeffcutt, 2000; Jeffcutt and Pratt, 2002; Luque, 2001; Lazzarato, 1996). A focus on embodied skills made it possible to 'rework terms such as talent, innovation and design and position them as key to the knowledge economy' (Lewis et al., 2007: 44).

Creativity became seen as a central method for generating knowledge, and thus competitive advantages in the workplace. While in Labour's policy it was the 'creatives' of the new economy - the software developers, graphic designers, filmmakers, new media workers, website engineers and artists - who were highlighted as embodiments of this new way of working (Oakley, 2006), in reality, creativity was to become expected across the economy at large. As Flew (2010: 162) notes "'soft skills" such as self-reflexivity, intuition, social competence and group responsibility are expected to be a part of the repertoire of creative people' in areas outside creative or cultural entrepreneurship. Creativity was to become, 'heterarchic, non-linear, reflexive and networked [where] ideas about a broadly distributed, non-elite creativity were joined to the innovation thinking of management gurus and business academics, representing creativity as unitary, universal and attuned to the real-life functioning of the economy' (Bill, 2016: 4).

This somewhat utopian doctrine, combined with substantive disinvestment in the UK HEl sector and broader changes in the UK economy, including a policy of austerity and increasing demand to demonstrate impact from public funding and cultural enterprise, set the conditions under which universities have become implicated in this creative turn (Moreton, 2016).

Bill (2016: 61) observes that creativity has 'come into focus as an object of university governance which extends to the university staff, its students, its civic duty to regional populations, and its contribution to the national economy'. This has been noticeable in the UK in four interconnected ways. First, as producers of research, academics are increasingly understood as knowledge entrepreneurs, where that knowledge is seen as a commodity. This has the added effect of marketing academics as the best, most innovative thinkers as a marketing tool to attract 'students as consumers' (Audretsch, 2014; Simons et al., 2009).

Second, as Osborne (2003: 509) points out, 'any glossary of business terms would reveal that creativity is increasingly susceptible to finesse through technique', and this assumption is visible in the changing forms of pedagogy in the university, where universities are now expected to support the generation of 'creative' students, with a set of skills and aptitudes that prepare them for the workforce (Comunian et al., 2011; Oakley, 2013).

Third, as civic bodies operating in the face of a drastically changing urban landscape, often itself subject to planning and development ideologies rooted in creativity, universities are implicated in the process of developing and working in the urban fabric in which they are situated, for example as landlords, business incubators or civic amenities (Benneworth, 2016).

Finally, universities are being caught in the interstices between two competing needs of an economy driven by creativity: the need to mobilize knowledge to generate economic value on the one hand, and/or the need to provide social impacts on the other. This has been frequently framed under the banner of the 'third mission', a loose collection of HEl activities outside of research and teaching that are designed to generate 'value' outside the academy. This is understood in terms of engagement with international partners, local and regional businesses, communities and industry through collaborative projects and co-investments, and through processes of knowledge exchange (Bullen et al., 2004; Hearn et al., 2004; Mould et al., 2009). 
The inflection of the third mission within creative sector HEl knowledge exchange work has been to establish universities as both 'pipelines' into, and caretakers of, a creative economy. This has been true to the extent that Universities UK, a consortium representing research-intensive UK universities, described the higher education sector as 'the primary producer of the talent and skills that feed the creative industries and an important source of research that informs new ideas, practices and business models, with applicability within and beyond the creative sectors' (UUK, 2010: iii).

\section{Governmentality, assemblage and policy mobility}

Schlesinger (2017) suggests that this approach to creativity is more a product of a normalizing doctrine than a specific policy family. Indeed, Osborne (2003: 508) argues that 'to suggest that this new ethos of creativity simply answers to structural needs [of the economy] would be to ignore the fact that the creativity explosion is also a product of human agency', that is, a product of a gradual but deliberate reconfiguration of the logics, conditions, rules, subjectivities and practices of contemporary life; it is, Osborne continues, 'as much a matter of our governmentality as of ideology'. Bill $(2016: 5,4)$ extends this point, arguing that 'creativity has now become part of the regulatory grammar of contemporary society', and alludes to the processes through which that regulation is performed, particularly as 'an object of governmental rationalities', and that despite its internal inconsistencies, creativity 'has already begun to change and structure the world it assumes to explain' (Dzudzek and Lindner, 2015: 2).

To understand how this has happened, Bill $(2016,2008)$ and others (Banks, 2009; Fougere and Solitander, 2010; Prince, 2013) have used approaches derived from Foucault's idea of governmentality. This approach relies on rethinking the term government as, 'the broad sense of procedures for directing human conduct' (Foucault, in Senellart, 2007: 388), and where governmentality refers to the ways in which those procedures are managed, more or less strategically, in line with distinctive rationalities and in order to achieve certain ends (Rose, 1999; Rose et al., 2006). In the context of the creative turn, governmentality provides 'an analytical toolbox' (Rose et al., 2006: 100) for unpacking the diffuse mechanisms and means by which 'creativity' as a mode of conduct has been legislated, nudged and encouraged. The focus shifts from an overarching rationality of governing a nation, or a state, towards an 'analytics of rule' that is applicable to a host of different institutions, populations and subjects (Dean, 2010: 33). A final key concept is the notion of the 'conduct of conduct'. This term refers to 'any attempt to shape with some degree of deliberation aspects of our behaviour according to particular sets of norms and a variety of ends' (Dean, 2010: 18), or, in other words, how practices of rule generate the conditions for people to act, without directly having to discipline those individuals into acting.

However, it is not an exhaustive approach, and many scholars have sought to expand this toolbox with other theoretical approaches (Brady, 2016). Assemblage theory looks at the matrix of human and non-human actors, processes, practices and territories - imagined, virtual, material - that come together in social, political and cultural life, representing:

a contingent and creative ensemble of ... knowledges, ways of seeing and calculating, human capacities, mundane and grand devices, kinds of authority, spatialities, and governmentalities ... that converge and which seek a specific outcome among those who govern and of those who are governed. (Lippert and Pyykkönen, 2012: 1) 
This approach has been useful in understanding how ideas and policies 'move' across contexts, something that creative economic logics most certainly have. Policy mobility literature has also done considerable work in this field, exploring how political ideologies and mundane processes, multiple governmentalities and competing knowledges are orchestrated through policy transfer. This term refers to 'the manner in which policy programmes developed in a particular time and place come to influence the development of a similar programme in another time or place' (Prince, 2010: 169). These processes have been understood in the literature as international or transnational, such as the movement of creative industry policy from one country to another (Prince, 2017, 2010; Rindzevičiūte et al., 2016), but also within nations and across industrial sectors (Ozga and Jones, 2006). The approach pays attention to the macro- and microscale performances of spatialization, knowing, power and measurement that 'make things happen' (Li, 2007). Prince (2017: 339) summarizes that policy mobility literature 'makes use of assemblage thinking to show how policy is constructed out of various circulating discourses and materials', including elements that exist both 'inside' and apparently 'outside' that assemblage.

Policy transfer points to a number of characteristics of the process of making ideas mobile. First, 'policies are not merely transferred over space but their formats and their effects are also transformed by their journey through professional communities, and through time' (Stone, 2017: 66). This means the policy object itself and its imagined impacts are modified in motion. Second, the sites of origin and arrival for policies are also transformed. Rindzevičiūte et al. (2016: 595) suggest that in the case of creative economies, the emergence of creative industries policy was a 'driver of wider change in the cultural policy field, re-arranging the existing practices and actoral identities'. Third, 'policy assembly through interpretation of different items of information and experience, often creates something new, that is, hybrids' (Stone, 2017: 66), meaning that the new thing being brought into being often bears characteristics of a number of its constituting agents. Fourth, due to this systemically transformative process, the effects will be felt whether the transfer has been a 'success' or a 'failure' (Stone, 2017: 66).

Munro $(2016,2017)$ shows that these characteristics are identifiable in creativeeconomy-university assemblages, not just in individual knowledge exchange partnerships between individual academics and companies, but also in the processes that manage them. Stone (2017: 62) describes these activities as a process of 'soft policy transfer' - 'the spread of ideas and diffusion of knowledge which is essential for providing the norms, evidence and (social) scientific understandings as to why it makes bureaucratic or political sense to transfer policy'. The case study of REACT that follows considers some of these processes to demonstrate how creative economy policy can be transferred, but also contested, through knowledge exchange activities.

\section{Assembling Research and Enterprise in Arts and Creative Technology (REACT)}

REACT was a collaboration between the University of the West of England (UWE), Bristol, and cinema, talent development and creative technology organization Watershed, also based in Bristol, along with the universities of Bath, Bristol, Cardiff and Exeter. The programme operated between 2012 and 2016, primarily by funding collaborative projects that featured at least one academic from a partner university, usually from an arts and humanities discipline, and one creative practitioner in the form of an artist, freelancer or business. These latter partners were drawn from across the UK. During its lifetime, REACT awarded $\mathbf{f 2 . 5}$ million in grants to 53 collaborations between 73 
academics and 55 businesses, the majority of which employed fewer than ten people. The brief was to develop 'prototype products or services' that could be exploited by the companies. At the centre of the REACT consortium was an existing relationship between UWE Bristol's Digital Cultures Research Centre (DCRC) and Watershed.

\section{Governance and local coalition building}

Bidding for the AHRC scheme of which REACT was a part began through 'town hall' consultation events, meetings, bid-writing sessions and other ad hoc engagements. Actors involved at this stage included senior university staff including pro-vice chancellors and deans, research officers, senior academics, CEOs and directors of cultural organizations in and around the South West, and representatives from the AHRC and its associated stakeholders at RCUK. It was the first time this combination of regional actors had worked together in this configuration, and bringing them together involved a complex and occasionally fractious process of what Rindzevičiūtè et al. (2016: 603) call 'local coalition building'. Legal, mundane and bureaucratic processes contracting, financial costings, human resources and logistics planning - were all integral in establishing the framework that allowed REACT to be established, even as an imaginary, within the bid.

After the bid was awarded - a process that involved interviews and written revisions of the proposal - the governance structure crystallized, with many of the actors who had set up the programme in leadership positions. The Operations Group managed the programme, comprising leads from the university partners (coinvestigators and the principal investigator, in UK research parlance) and Watershed. A Steering Board providing oversight was comprised of senior-level university staff who had been involved in the brokering of the original collaboration, as well as senior figures from the cultural and creative sector in Bristol, including Watershed's CEO. An Advisory Group was drawn together from the creative sector, and included representatives from film, television, computer game development, advertising, innovation, animation, and cultural organizations such as theatres. While power was largely devolved to the Operations Group and delivery teams, this framework was dominated by university staff, processes and procedures, and often threatened to occlude other forms of institutional knowledge and practice. This was visible in the manner that Watershed - a lead partner who were central to the delivery of REACT - were required to be engaged as 'subcontractors', as AHRC rules at that time precluded them from being represented as co-investigators, even though Watershed brought with them the central network of organizations and actors working within and adjacent to the creative economy upon which the project was based.

\section{Establishing discourses of knowledge exchange}

The underpinnings of the REACT model were based upon an approach to supporting innovation in the arts and 'creative technology' sector developed by DCRC and Watershed, who had been working together for a number of years. Creative technology refers to the application of new or emerging technologies in an artistic and cultural context to find alternative, usually socially progressive and human-centred, contexts for that technology. Examples include the expansion of theatrical experiences with augmented reality, or site-specific heritage interpretations using GPS data and locative software to deliver new engagements with sites.

This approach (Bachmann et al., 2012) sought to establish a model of understanding the value of creative and cultural work that recognized both the inputs and outputs of 
labour as being 'more than' economic. The central tenet of the approach was that by bringing together practitioners from different sectors, disciplines and communities, networks could be aggregated to increase mutual support, serendipity, new work or ideas exchange, and resilience by mobilizing connections between microbusiness and freelancers. The outcomes, it was argued, were strong networks with multiple forms of emergent value that included, but were not reducible to, economic outputs. This was most clearly exemplified in Producing the Future: Understanding Watershed's role in ecosystems of cultural innovation, a report produced for Watershed by Graham Leicester and Bill Sharpe at the International Futures Forum (Leicester and Sharpe, 2010).

This theoretical position - which explicitly resists linear, 'growth to acquisition' commercial processes for R\&D - underpinned the primary knowledge exchange methodology adopted by REACT: a three-month R\&D process devised by Watershed, known as a 'Sandbox'. Each Sandbox comprised six to eight collaborations working on discrete projects around a common theme. Themes were identified in partnership with the Advisory Board, and included heritage, publishing, interactive documentary and children's products. There was a parallel scheme for collaborations which did not find a home in the thematic or temporal constraints of the Sandboxes, referred to as the 'Strategic Fund'. The average award to Sandbox collaborations was $f 50,000$. The money supported academic time, awarded a $£ 10,000$ grant towards company time, and provided a production budget, and travel, subsistence and other costs associated with the delivery of the projects. Strategic Funds typically featured grants ranging between $£ 5,000$ and $£ 20,000$. A follow-on scheme which partnered with an investment firm and business development specialists was conceived halfway through the programme to experiment with 'grow on' processes for early-stage ideas developed in the core programme.

Watershed's Sandbox method predated REACT, and was first launched in 2007 to provide creative start-ups with time and space to conduct R\&D. REACT adapted this methodology by building in collaborative and interdisciplinary partnerships. Under REACT, Sandbox became a method for bringing people together in an ideas generation and prototyping process. It was a three-month mentored programme, heavily curated by dedicated team members, which emphasized peer learning, iterative design and open sharing of ideas. Workshops on business development, prototyping, audiences and public relations were all part of a programme of regular meetings in which the cohort could share ideas, seek out additional skills from one another, and otherwise share the process.

The role of the 'creative producer' was central to this form of collaborative practice. These are individuals who act 'as a creative, administrative, diplomatic and brokering force holding the collaborations together, whilst also helping to develop levels of ambition in terms of markets, products and creative practices' (Dovey et al., 2016: 19). The notion of the creative producer was core to Watershed's approach to managing communities, and also predated REACT. The role itself emerged from a broader shift in the terrain of arts management, which increasingly identified a complex administrative, curatorial, creative and strategic skill set crystallizing in many areas of cultural work (Tyndall, 2007). These types of cultural intermediaries have been recognized in other parts of the creative economy (Virani and Pratt, 2016).

Despite drawing from what could be considered work on 'diverse economies' (Gibson-Graham, 2006), both the role of the producer and the model of Sandbox fold discourses about intrinsic cultural value, collaboration, novelty, ideation and collectivist approaches into existing innovation literature. 'Creation nets' (Hagel III 
and Seely Brown, 2006), for example, were cited by Watershed as a key influence. Associated with models of 'open' or 'distributed' innovation (Lakhani and Panetta, 2007), this approach entailed 'a set of institutional mechanisms designed to mobilize independent entities in the pursuit of distributed, collaborative and cumulative innovation' (Hagel III and Seely Brown, 2006: 5). This hybrid became formalized as a set of values for the programme: supporting risk, curating diversity (of approach, talent and background), sharing process, building community and caring for participants (Lansdowne, 2016).

In this way, alternative models of creative labour were incorporated into REACT from management literature, and although they featured elements of market-driven commercial creativity, these were not reducible to the normative model often proposed by existing creative policy, in that they emphasized the excessive, human-centred and collective impetus of generating value beyond the economic.

\section{Subjects of knowledge exchange}

Managing and imagining the subjects of these innovation practices, however, was not straightforward. In an early Working Paper for REACT based on interviews with participants, I wrote that:

discursive frameworks operate as day-to-day short-hands. They connote assumptions - sometimes unconscious and sometimes conscious - about the abilities or predispositions of our collaborators ... Academics are cast as deeply knowledgeable, curious creatures, but slow moving, and obscure, with a tendency toward abstraction. Creative businesses are pitched as lean, hungry, agile and focussed, sinking or swimming by the quality of their product. (Moreton, 2018: 4)

This statement was born out of an awareness of the complexity of the subject positions with which knowledge exchange in this field deals. Creative and knowledge economy policies have arguably envisaged flexible, 'creative' or 'knowledge' workers as being associated with 'more complex forms of subjectivity than those associated with clearly demarcated working practices and disciplined subjectivities' (Edwards and Nicoll, 2004: 163-4). They represent actors within a system where there are new expectations of the type of work that they do, and also the way that they are treated and how their actions are valued. Moreover, as Mould (2018) and others (McGuigan, 2010) have pointed out, creativity represents a contradictory paradigm - both aggressively individualizing and culturally collective, very often entailing exploitation of the self, dressed up as emancipation. These attitudes towards creative labour - and creativity in labour - are not restricted to the creative sector. Resistance to the same discourses at work in academic institutions has been identified, where increasing levels of selfexploitation and 'entrepreneurialization' of research life have been noted (Gill, 2014; Gill and Donaghue, 2016).

Internalized assumptions about professional identities, forged over long periods of time and across multiple spaces, are not easy to challenge, and, in this sense, the assemblage formed by REACT operated between a number of competing professional and political domains, in which subjective identities were often seen as fixed entities. For example, the assumption that creatives work fast, relentlessly, fluidly and with energy has produced (or been produced by) unhealthy work cultures - such as working long hours, to tight deadlines, to achieve creative goals (Moore and Taylor, 2009) - which were embedded in the processes we ran. At the same time, participants from outside academia spoke regularly in interviews of the fact that creative work is 
also slow and deliberative, and it is commercial constraints that make their work seem otherwise.

We also found that most academics were comfortable - perhaps because they had self-selected to participate in REACT - with ideas about commercialization, albeit assuming they would not be the ones taking an idea to market. To some extent, this contrasts with Vostal and Robertson's (2012: 144-5) observations that commercialization is viewed suspiciously in academic cultures, 'in part because the traditions of "good" academic practice - disinterestedness, scepticism and rationality - sit uneasily with the demands of a business venture, such as passion, pace and risk'.

Many of our academic participants believed that REACT offered them the chance to explore alternative forms of epistemological and pedagogic opportunities. For these participants, REACT represented a chance to carry out activistic work in a context where, for many academics, an attempt at 'deepening their political intervention beyond academia was ... perceived [by HEls] as a practice incompatible with the production of rigorous and credible academic knowledge', as Pereira (2016: 102) notes. In this sense, attitudes of academics in the programme wishing to 'make a difference' were recognizable in REACT and, as Larner (2012: 289) suggests, 'while these new formulations are still very much in the making, they relate to new aspirations for knowledge-making that move well beyond the "knowledge transfer" models that currently dominate the thinking of universities and governments'.

\section{Spatialities and temporalities of knowledge exchange}

REACT was part of a national network of partners, but also had to orchestrate a 'coming together' of regional actors to 'collaborate' around a locus in Bristol. This meant negotiating a number of nested scales, balancing variance in infrastructure, such as creative workplaces, business connections and other resources, within the REACT region, while also formalizing the REACT region as a unitary cluster in national conversations. A specific territory of creative work became the site through which REACT operated. This was the Pervasive Media Studio (PM Studio), a space that provided both a home for DCRC and REACT in Watershed's central Bristol building. The PM Studio was established in 2008 by Watershed, and latterly funded by Watershed, the University of Bristol and UWE Bristol. It is a co-working space, managed through a residency scheme, in which academics, artists, creative practitioners, businesses and others explore interdisciplinary, cultural and commercial applications of emergent technology. Its management processes, including its curatorial position, were heavily influenced by the ideas around creation nets and value cited previously.

Space here does not represent a terrain upon which government is performed, but instead is constituted through rule by the processes of government that imagine, divide, regulate and otherwise describe spatial arrangements (Elden, 2007; Huxley, 2006; Rose, 1999). Although the spatial logic of REACT focused primarily on the 'networked' or 'ecological', the programme design relied on the need for proximity, co-location and curated venues in which collaboration could be supported. The PM Studio became the focus for the funded collaborations, where workshops and meetings would take place, and where participants could meet, work, share ideas and develop their projects. University sites were considered less effective for this process, due to their geographical isolation in campuses or precincts, and their often unnavigable layouts. This speaks to work on 'third spaces' as a place outside of the working environments of everyday work, where academics and creative companies can interact (Comunian and Gilmore, 2016), but it also reinforces existing discourses about how co-working or laboratory spaces can generate buzz, hype and ideas. 
The complicated reality of having a hub based in one city in the collaboration, as well as a multi-partner consortium engaged in regional development activities, meant that spatial scales were hard to navigate. While events were held in Exeter, Cardiff, Bath and Bristol, the challenge remained of how to develop resources equitably across the region - especially where those distributed spaces were subject to other forms of governance, managed differently, or constituted around competing or contrasting versions of what 'creative' work might represent. In this sense, REACT's attempts to balance the need for a spatial 'epicentre' and a distributed mode of production struggled to take into account how the different actors in the assemblage - particularly universities in sites where there was no equivalent to the PM Studio - had more agency or exerted different forms of management over the working environment.

Time, its government, management and performance were central to REACT. This included the rates at which parties were anticipated to work and the speed at which things happened in the assemblage, as well as the discursive significance of time-based analogies for the production of creative knowledge.

As we have seen, the temporalities of work already played a part in establishing preconceptions about how participants were expected to work while engaging in knowledge exchange, but specific and sometimes bureaucratic processes of temporal management were necessary to deliver the programme. These took a number of forms. In relation to projects, emphasis was placed on the discourse of 'time out' from existing work and responsibilities, including academic teaching, research and administrative work, and client-facing, day-to-day work for creative businesses. Voucher-based schemes where participants 'took the money and ran' were eschewed in favour of longerterm relationships in which participants could 'develop'. This required a negotiation of the practical reality that academic processes and research programmes operate over long timescales, often three to five years, and long publishing or dissemination time frames. Similarly, the experience of many micro- and medium-sized enterprises and freelancers, particularly those precariously engaged in the creative economy, was one of rapid turnarounds for clients, meeting short-term deadlines.

The normative governmentality of 'working at velocity' was only partially addressed. While we spoke about 'buying time' for companies to engage in R\&D, existing binaries between different actors in the collaborations were still reinforced, in part because they themselves had absorbed and performed those identities outside of REACT. We noted that both academic and creative participants invested more time in their projects than was covered by their contracts with us. In the case of academics, this would mean additions to already burgeoning workloads, but which would not have a direct impact on their remuneration. In the case of creative participants, however, this meant they were essentially working for free, or 'self-investing' in the development of an idea - meaning that they were not taking on work from other sources, and that the $£ 10,000$ grant was having to be stretched further. In this instance, time was understood as evidence of 'skin in the game', an entrepreneurial shorthand for demonstrating commitment to an idea via self-investment. In truth, this materially disadvantaged the non-academic participants more than the academics.

Other instances in which reconfiguring time was a managerial component of our work involved addressing the slower parts of university administrative systems, particularly contracting and finance. In HEls, smaller companies and individuals are often subject to the same payment terms as bigger businesses and organizations, and, in the experience of REACT, smaller payments to companies could take months. This was untenable for participants whose income during this time was reliant on the consortium to survive. The solution was to build relationships with individuals in 
research offices, finance departments and contracting services, who could expedite payments, find solutions within the system and otherwise support this process. This adjusted the temporalities in small ways in other parts of the university. These relationships expanded the actors in the assemblage, and made visible the true extent of the changes and shifts needed to deliver even modestly funded knowledge exchange projects.

Finally, regular funder monitoring cycles, including six-monthly qualitative and quantitative reporting, generated a rhythm for the production of evidence. Data collection was monitored and carried out by the Research Fellow through interviews, surveys and focus groups. Participants were contractually obliged to speak to members of the team for evaluation purposes, and to provide information upon request.

While systems were developed to protect participants from the potentially extractive nature of data collection, the competing rhythms of project management, Sandbox delivery, 'creative' production of innovation, and different timescales of work across multiple institutions, it was clear that different temporalities were constantly vying for prominence in the work of the programme, and the assemblage was dependent on a range of competing and contrasting temporalities to which we, and our funded participants, were subject and which, paradoxically, we also created ourselves as a consequence of the assemblage's many moving parts.

\section{Calculating and codifying value and impact}

Calculative practices take a wide variety of forms (Hannah, 2000; Miller, 2004; Miller and O'Leary, 1994; Rose-Redwood, 2008, 2006). They render government technical by recourse to numbers as incontrovertible representations of truth, where, in fact, they are political outcomes used to promote a way of governing as 'objective' and thus legitimate (Rose, 1999: 199). The creative sector itself is a product of calculative imaginaries which have sought stability through statistics and distinctive classifications of inputs, outputs and workers. These have enabled the sector to appear 'stabilised with a constellation of characteristics, allowing them to be compared with other sectors or types of economic activity' (Wilson, 2010: 370).

The emergence of the term 'creative economy' has further extended the calculative imaginary of the creative industries beyond its initial definitions, mobilizing a range of statistical methodologies to identify where 'creative labour' resides in other areas of the economy outside the creative industries, while also removing 'noncreative' roles from calculations about the creative industries (Bakhshi et al., 2013). REACT adopted the term 'creative economy' as a shorthand for the domain of its primary beneficiaries, in an attempt to broaden the scope of those practices seen as creative which might otherwise be invisible to funders. This was in keeping with the approach to 'creative ecosystems' and the generation of cultural value supported by both the programme and the AHRC (Holden, 2015). Nonetheless, the adherence to a creative economy discourse built on measurements and metrics still triangulated the 53 funded projects within an economic discourse in which the AHRC and HEls (and thus the assemblage) were heavily implicated (Moreton, 2018).

This was compounded by the performance measurement process required of REACT by its funders. During the lifetime of the programme, the project was committed to a series of key performance indicators (KPIs). These were designed in consultation with the AHRC during and after the bidding process. They measured volumes of engagement (such as numbers of bids to our funding calls, and attendees at events) and material outcomes (money generated by projects, further investment in companies, and products and services released to market). Rather than monitoring 
metrics, these KPIs represented tools of regulation to ensure that targets were met even where those targets might not be accurate representations of what the project deemed as 'success' - including job creation statistics, broadly recognized to be inaccurate indicators of change in a creative sector where freelance labour, short-term contracts and non-wage-drawing directors of companies are the norm (Haans and van Witteloostuijn, 2018). This rendered the work of knowledge exchange technical and quantitative, focusing on outputs over process.

These KPls and other supplementary evidence were codified in the regular reporting processes mentioned previously, in the final report submitted to the AHRC, and in a public-facing report produced by the Operations Group and Research Fellow. These latter documents utilized the same numbers and calculations to evidence economic growth and value for public money, but they did not always capture the complexity of the processes at work. The use of these calculative practices bound REACT into a process of normalization, decomplexifying its outcomes by resorting to established metrics. Although this made REACT's activities legible nationally by ensuring that they were commensurate with other recipients of funding and available to be used in other policy spaces, those other political assemblages may not have engaged with the complexity of the processes that produced those outputs. This is because on-the-ground changes, emerging from the constant and contradictory negotiation of different discourses about creativity and innovation, are hard to make legible for institutional governmentalities that are rarely equipped to legislate for that complexity.

Finally, given the relative novelty - in both focus and scale - of the Hubs programme, members of the REACT team were often engaged in articulating the complex discursive underpinnings of REACT to policy audiences. Academic-led Working Papers were produced as a means of providing reflection both on and for the programme, as well as sharing with wider audiences. Talks were given at ninety conferences and industry events, including to government audiences via the Department for Business, Innovation and Skills (BIS, now the Department for Business, Energy and Industrial Strategy (BEIS)). REACT became instrumental in producing what Brenneis (2012) has called 'metaexperts' in the university, who advocate, manage, bid for and deliver programmes of this kind. As he points out, 'such metaexperts are not administrators or entrepreneurs; they are rather scholars, scientists and departments who serve as consultants in shaping the new languages and practices of university governance' (Brenneis, 2012: 296). In this way, the REACT team became implicated in informing the architecture of future knowledge exchange policies, inside and outside the university, but retained little agency in how that architecture would be established.

\section{Concluding remarks}

It is inescapable that REACT was part of a broader movement that has positioned HEls as 'stewards' of the creative sector, operating at an imagined interface of care, support and expertise to a nascent, small, agile, but vulnerable creative economy (Munro, 2017). Despite the alternative models or ideas at work in REACT, like other knowledge exchange projects in this area, it nonetheless operated 'to organise and govern creative production and to keep creative practitioners aligned with high level cultural and creative-economic policy' (Munro, 2017: 14).

Virani and Pratt (2016), in their work on Creative Works London, point out that universities operating as intermediaries in the creative economy, and explicitly in knowledge exchange, are not passive actors (see also Gibson, 2015; Osborne, 2004; 
Vostal and Robertson, 2012). Instead, they are active agents in the management, production, translation, agenda setting and day-to-day work of brokering, designed to facilitate collaboration between sectors by importing existing and sometimes fragmentary ideas about creativity to rationalize, shape and mobilize their activity (Munro, 2017, 2016).

The example of REACT demonstrates how multi-institution assemblages fulfil this intermediary role. As Prince (2017) notes, such assemblages never fully cohere, and are fundamentally prone to being destabilized from within by changes to the balance of actions, actors, things and people that constitute them. In this sense, they are constantly shifting and adapting and being recomposed by the efforts of those either constituting or subject to constitution, by the process of assembling. The messy day-to-day delivery of such knowledge exchange programmes - the act of bringing together the various actors, agencies, stakeholders, ideologies, practices, places and so on - and not just the active participants transacting 'the exchange', constitute this assemblage, and it is through these processes that different creative economic rationales are brought into being. This paper provides only a snapshot of these processes and the multiple acts of governing and adaptation associated with them, but it shows how these processes are interrelated, interdependent and simultaneous. They are both effects of the assemblage, and a part of the assemblage itself. They abide by contrasting temporal and spatial logics through which the techniques of government, particularly in relation to space, time, subject positions and calculation, are performed.

By looking at the 'coming together' of REACT through various practical, cultural and administrative means, we can see how and where these ideas and policies are made mobile in a way that both adapts creative work to its new context, and also adapts universities to accommodate these hybrid approaches. By paying attention 'to the tactics and strategies of policy resistance by "subordinate recipient actors"' (Stone, 2017: 61, emphasis in original), the assemblage underpinning REACT demonstrates through its attempts to assemble multiple and contrasting approaches to knowledge exchange - how creative economy governmentalities are performed at a distance through such programmes, but never in totality. As a space of policy transfer, REACT represented neither an independent epistemological space, nor a frictionless conduit for existing policy ideas about the creative economy, because it operates at all these contradictory scales.

Nonetheless, in the years since REACT finished, there has been a proliferation of funding programmes seeking to further an agenda of creative economy-university collaboration, and specifically regional economic development at arm's length through knowledge exchange (Williams et al., 2018). The momentum of many of these programmes has been facilitated by the Industrial Strategy Challenge Fund. This scheme was part of a $f 4.7$ billion investment in R\&D announced in 2017 . The fund was specifically designed to 'bring together our world-leading research base with Britain's best businesses to transform how we live, work and move around' (GOV.UK, 2017: n.p.). Even though at first creative industries were absent from the White Paper, lobbying from the Creative Industries Council and an independent review by Peter Bazalgette (2017) have led to funding from the scheme being channelled to universities via UKRI, Research England and the AHRC. The AHRC's Creative Industries Clusters Programme (CICP), which emerged from this funding, represents a scaling-up of the Hubs programme. UWE Bristol, Watershed and the universities of Bath, Bath Spa and Bristol are now leading one of nine CICP programmes, Bristol+Bath Creative R+D. In Wales, Creative Cardiff, a regional development initiative for the creative economy formed as a REACT legacy, are currently running another CICP programme called 
Clwstwr. Furthermore, at the time of writing, a successful $£ 30$ million bid to the UKRI/ Innovate UK Strength in Places Fund led by the University of Bristol, and collaborating again with regional HEls, has been awarded to focus on the creative industries in the Bristol and Bath city region.

These schemes, however, have as their rationale the growth and expansion of the creative sector through university knowledge, leading to new jobs, new IP and technology, and new wealth, and it is not clear how much impact even the modest counter-flows of REACT have had on the landscape. A lack of focus within REACT on questions of inclusion, representation and social justice means that the creative economy with which we engaged largely remained white and middle class (Banks, 2017; Finkel et al., 2017), and did little to advance equality in the sector. (It is worth noting that the consortium partners, particularly Watershed, have invested heavily in this area of research and practice in the years since REACT, and these questions now sit at the heart of Bristol+Bath Creative R+D.) Further, the events of the last four years, ranging from the rise of populism, to Brexit and the COVID-19 pandemic, have demonstrated an increasingly fraught and fragmented economic, political and social system, with creative and cultural workforces destabilized (Comunian and England, 2020).

But government and popular calls to 'build back better' may yet offer chances for a different form of economy to emerge, not based only on problematic assumptions about creativity. But as those working at the intersection of these creative economic$\mathrm{HEI}$ domains, we must remain vigilant to how we are reinforcing problematic concepts of market-driven creativity through our work, even when we are trying our hardest to reimagine those concepts as something brighter or more progressive.

\section{Acknowledgements}

My thanks to the two anonymous reviewers for their encouraging and spot-on critiques.

\section{Notes on the contributor}

Simon Moreton is Senior Research Fellow at the Creative Economies Lab, part of the Digital Cultures Research Centre at the University of the West of England, Bristol, UK. His work explores how political and economic agency is ascribed to the concept of 'creativity'. He is Co-Investigator on the Bristol+Bath Creative R+D (AHRC) programme, where he heads up its evaluation and research strategy. He is also exploring diverse and post-capitalist models for the creative economy in the University of Bristol-led 'My World' programme.

\section{References}

AHRC (Arts and Humanities Research Council) (2011a) AHRC Knowledge Exchange Hubs for the Creative Economy: FAQs. Swindon: AHRC.

AHRC (Arts and Humanities Research Council) (2011b) AHRC Knowledge Exchange Hubs for the Creative Economy: Call for expressions of interest. Swindon: AHRC.

Audretsch, D.B. (2014) 'From the entrepreneurial university to the university for the entrepreneurial society'. The Journal of Technology Transfer, 39, 313-21. https://doi.org/10.1007/s10961-0129288-1.

Bachmann, G., Dovey, J., Monaco, J. and Sharpe, B. (2012) Cultural Value Networks. Accessed 14 June 2021. https://culturalvalue.dcrc.org.uk/wp-content/uploads/sites/7/2015/10/ AHRCConCom_CulturalValueNetworks.pdf. 
Bakhshi, H., Hargreaves, I. and Mateos-Garcia, J. (2013) A Manifesto for the Creative Economy. London: Nesta. Accessed 3 June 2021. https://media.nesta.org.uk/documents/a-manifesto-forthe-creative-economy-april13.pdf.

Banks, M. (2009) 'Fit and working again? The instrumental leisure of the "creative class"'. Environment and Planning A: Economy and space, 41 (3), 668-81. https://doi.org/10.1068/a40333.

Banks, M. (2017) Creative Justice: Cultural industries, work and inequality. London: Rowman and Littlefield.

Bazalgette, P. (2017) Independent Review of the Creative Industries. Accessed 13 June 2021. www.gov.uk/government/publications/independent-review-of-the-creative-industries.

Bell, D. (1973) The Coming of Post-Industrial Society: A venture in social forecasting. Harmondsworth: Penguin.

Benneworth, P. (2016) 'Tensions in university-community engagement: Creative economy, urban regeneration and social justice'. In R. Comunian and A. Gilmore (eds), Higher Education and the Creative Economy: Beyond the campus. London: Routledge.

Bill, A. (2008) 'Creative Girls: Fashion design education and governmentality'. PhD thesis, University of Auckland.

Bill, A. (2016) 'Counter-conduct in creative university research: Deliberations on freedom'. Higher Education Research \& Development, 36 (2), 241-54. https://doi.org/10.1080/07294360.2016.1208 158.

Brady, M. (2016) 'Neoliberalism, governmental assemblages, and the ethnographic imaginary'. In M. Brady and R.K. Lippert (eds), Governing Practices: Neoliberalism, governmentality, and the ethnographic imaginary. Toronto: University of Toronto Press, 3-32.

Brenneis, D. (2012) 'Translation, time and the third mission'. Social Anthropology, 20 (3), $294-7$. https://doi.org/10.1111/j.1469-8676.2012.00212.x.

Bullen, E., Robb, S. and Kenway, J. (2004) '"Creative destruction": Knowledge economy policy and the future of the arts and humanities in the academy'. Journal of Educational Policy, 19 (1), 3-22. https://doi.org/10.1080/0268093042000182609.

Comunian, R. and England, L. (2020) 'Creative and cultural work without filters: Covid-19 and exposed precarity in the creative economy'. Cultural Trends, 29 (2), 112-28. https://doi.org/10.10 80/09548963.2020.1770577.

Comunian, R. and Gilmore, A. (eds) (2016) Higher Education and the Creative Economy: Beyond the Campus. London: Routledge.

Comunian, R., Faggian, A. and Jewell, S. (2011) 'Winning and losing in the creative industries: An analysis of creative graduates' career opportunities across creative disciplines'. Cultural Trends, 20 (3-4), 291-308. https://doi.org/10.1080/09548963.2011.589710.

DCMS (Department for Digital, Culture, Media and Sport) (1998) 'Creative industries mapping documents 1998'. Accessed 13 June 2021. www.gov.uk/government/publications/creativeindustries-mapping-documents-1998.

DCMS (Department for Digital, Culture, Media and Sport) (2001) 'Creative industries mapping documents 2001'. Accessed 13 June 2021. https://www.gov.uk/government/publications/ creative-industries-mapping-documents-2001.

DCMS (Department for Digital, Culture, Media and Sport) (2008) Creative Britain: New talents for the new economy. Accessed 13 June 2021. https://static.a-n.co.uk/wp-content/uploads/2016/12/ Creative-Britain-new-talents-for-the-new-economy.pdf.

Dean, M. (2010) Governmentality: Power and rule in modern society. London: Sage.

Dovey, J., Moreton, S. and Hargreaves, I. (2016) The REACT Report: 2012-2016. Bristol: REACT.

Dzudzek, I. and Lindner, P. (2015) 'Performing the creative-economy script: Contradicting urban rationalities at work'. Regional Studies, 49 (3), 388-403. https://doi.org/10.1080/00343404.2013.8 47272.

Edwards, R. and Nicoll, K. (2004) 'Mobilizing workplaces: Actors, discipline and governmentality'. Studies in Continuing Education, 26 (2), 159-73. https://doi.org/10.1080/158037042000225191.

Elden, S. (2007) 'Governmentality, calculation, territory'. Environment and Planning D: Society and space, 25 (3), 562-80. https://doi.org/10.1068/d428t.

Finkel, R., Jones, D., Sang, K. and Stoyanova Russell, D. (2017) 'Diversifying the creative: Creative work, creative industries, creative identities'. Organization, 24 (3), 281-8. https://doi.org/10.1177/1350508417690167.

Flew, T. (2010) 'Creativity, the "new humanism" and cultural studies'. Continuum: Journal of Media and Cultural Studies, 18 (2), 161-78. https://doi.org/10.1080/1030431042000214979.

Fougere, M. and Solitander, N. (2010) 'Governmentality and the creative class: Harnessing Bohemia, diversity and freedom for competitiveness'. International Journal of Management Concepts and Philosophy, 4 (1), 41-59. https://doi.org/10.1504/IJMCP.2010.031301. 
Garnham, N. (2005) 'From cultural to creative industries: An analysis of the implications of the "creative industries" approach to arts and media policy making in the United Kingdom". International Journal of Cultural Policy, 11 (1), 15-29. https://doi.org/10.1080/10286630500067606.

Gibson, C. (2015) 'Negotiating regional creative economies: Academics as expert intermediaries advocating progressive alternatives'. Regional Studies, 49 (3), 476-9. https://doi.org/10.1080/003 43404.2014.945249.

Gibson-Graham, J.K. (2006) A Postcapitalist Politics. Minneapolis: University of Minnesota Press.

Gill, R. (2014) 'Academics, cultural workers and critical labour studies'. Journal of Cultural Economy, 7 (1), 12-30. https://doi.org/10.1080/17530350.2013.861763.

Gill, R. and Donaghue, N. (2016) 'Resilience, apps and reluctant individualism: Technologies of self in the neoliberal academy'. Women's Studies International Forum, 54, 91-9. https://doi.org/10.1016/j.wsif.2015.06.016.

GOV.UK (2017) 'Industrial Strategy Challenge Fund: For research and innovation'. Accessed 11 April 2021. www.gov.uk/government/collections/industrial-strategy-challenge-fund-joint-research-andinnovation.

Grant, R.M. (1996) 'Toward a knowledge-based theory of the firm'. Strategic Management Journal, 17 (S2), 109-22. https://doi.org/10.1002/smj.4250171110.

Haans, R.F.J. and van Witteloostuijn, A. (2018) 'Expected job creation across the cultural industries: A sectoral division and its implications for cultural policy'. International Journal of Cultural Policy, 24 (1), 45-67. https://doi.org/10.1080/10286632.2015.1128420.

Hagel III, J. and Seely Brown, J. (2006) Creation Nets: Harnessing the potential of open innovation. Accessed 13 June 2021. www.johnhagel.com/creationnets.pdf\#: :text=Creation\%20nets\%20 represent\%20a\%20particularly\%20powerful\%20form\%20of,activity\%20pursued\%20by\%20 hundreds\%20or\%20thousands\%20of\%20participants.

Haner, U.E. (2005) 'Spaces for creativity and innovation in two established organizations'. Creativity and Innovation Management, 14 (3), 89-96. https://doi.org/10.1111/j.1476-8691.2005.00347.x.

Hannah, M.G. (2000) Governmentality and the Mastery of Territory in Nineteenth-Century America. Cambridge: Cambridge University Press.

Hayek, F. (1945) 'The use of knowledge in society'. The American Economic Review, 35 (4), 519-30. https://www.jstor.org/stable/1809376.

Hearn, G., Cunningham, S. and Ordoñez, D. (2004) 'Commercialisation of knowledge in universities: The case of the creative industries'. Prometheus, 22 (2), 189-200. https://doi.org/10.1080/081090 2042000218364.

Holden, J. (2015) The Ecology of Culture: A report commissioned by the Arts and Humanities Research Council's Cultural Value Project. Accessed 13 June 2021. https://ahrc.ukri.org/ documents/project-reports-and-reviews/the-ecology-of-culture/.

Huxley, M. (2006) 'Spatial rationalities: Order, environment, evolution and government'. Social and Cultural Geography, 7 (5), 771-87. https://doi.org/10.1080/14649360600974758.

Jeffcutt, P. (2000) 'Management and the creative industries'. Studies in Cultures, Organizations and Societies, 6 (2), 123-7. https://doi.org/10.1080/10245280008523543.

Jeffcutt, P. and Pratt, A.C. (2002) 'Editorial: Managing creativity in the cultural industries'. Creativity and Innovation Management, 11 (4), 225-33. https://doi.org/10.1111/1467-8691.00254.

Lakhani, K.R. and Panetta, J.A. (2007) 'The principles of distributed innovation'. Innovations: Technology, Governance, Globalization, 2 (3), 97-112. https://doi.org/10.1162/itgg.2007.2.3.97.

Lansdowne, J. (2016) Watershed Sandbox: A how to guide. Making space for great ideas. Bristol: Watershed.

Larner, W. (2012) 'Beyond commercialisation'. Social Anthropology, 20 (3), 287-9. https://doi.org/10.1111/j.1469-8676.2012.00209.x.

Lazzarato, M. (1996) 'Immaterial labour'. In P. Virno and M. Hardt (eds), Radical Thought in Italy: A potential politics. Minneapolis: University of Minnesota Press, 133-47.

Leicester, G. and Sharpe, B. (2010) Producing the Future: Understanding Watershed's role in ecosystems of cultural innovation. Bristol: Watershed. Accessed 13 June 2021. www.watershed. co.uk/sites/default/files/publications/2011-03-15/Watershed_IFF_Report_online.pdf.

Lewis, N., Larner, W. and Le Heron, R. (2007) 'The New Zealand designer fashion industry: Making industries and co-constituting political projects'. Transactions of the Institute of British Geographers, 33 (1), 42-59. https://doi.org/10.1111/j.1475-5661.2007.00274.x.

Li, T.M. (2007) The Will to Improve: Governmentality, development, and the practice of politics. Durham, NC: Duke University Press.

Lippert, R.K. and Pyykkönen, M. (2012) 'Introduction: Immigration, governmentality, and integration assemblages'. Nordic Journal of Migration Research, 2 (1), 1-4. https://doi.org/10.2478/v10202011-0021-1. 
Luque, E. (2001) 'Whose knowledge (economy)?'. Social Epistemology, 15 (3), 187-200. https://doi.org/10.1080/02691720110076521.

McGuigan, J. (2010) 'Creative labour, cultural work and individualisation'. International Journal of Cultural Policy, 16, 323-35. https://doi.org/10.1080/10286630903029658.

Miller, P. (2004) 'Governing by numbers: Why calculative practices matter'. In A. Amin and N. Thrift (eds), The Blackwell Cultural Economy Reader. Oxford: Blackwell, 179-89.

Miller, T. (2009) 'From creative to cultural industries: Not all industries are cultural, and no industries are creative'. Cultural Studies, 23 (1), 88-99. https://doi.org/10.1080/09502380802326660.

Miller, P. and O'Leary, T. (1994) 'Accounting, "economic citizenship" and the spatial reordering of manufacture'. Accounting, Organizations and Society, 19 (1), 15-43. https://doi.org/10.1016/0361-3682(94)90011-6.

Moore, P. and Taylor, P.A. (2009) 'Exploitation of the self in community-based software production: Workers' freedoms or firm foundations?' Capital and Class, 33 (1), 99-119. https://doi.org/10.1177/030981680909700106.

Moreton, S. (2016) 'Rethinking "knowledge exchange": New approaches to collaborative work in the arts and humanities'. International Journal of Cultural Policy, 22 (1), 100-15. https://doi.org/10.1080/10286632.2015.1101081

Moreton, S. (2018) 'Contributing to the creative economy imaginary: Universities and the creative sector'. Cultural Trends, 27 (5), 327-38. https://doi.org/10.1080/09548963.2018.1534575.

Mould, O. (2018) Against Creativity. London: Verso.

Mould, O., Vorley, T. and Roodhouse, S. (2009) 'Realizing capabilities - Academic creativity and the creative industries'. Creative Industries Journal, 1 (2), 137-50. https://doi.org/10.1386/ cij.1.2.137_1

Munro, E. (2016) 'Illuminating the practice of Knowledge Exchange as a "pathway to impact" within an Arts and Humanities Research Council "Creative Economy Knowledge Exchange" project'. Geoforum, 71, 44-51. https://doi.org/10.1016/j.geoforum.2016.03.002.

Munro, E. (2017) 'Building soft skills in the creative economy: Creative intermediaries, business support and the "soft skills gap"'. Poetics, 64, 14-25. https://doi.org/10.1016/j.poetic.2017.07.002

Oakley, K. (2004) 'Not so cool Britannia: The role of the creative industries in economic development'. International Journal of Cultural Studies, 7 (1), 67-77. https://doi.org/10.1177/1367877904040606.

Oakley, K. (2006) 'Include us out - Economic development and social policy in the creative industries'. Cultural Trends, 15 (4), 255-73. https://doi.org/10.1080/09548960600922335.

Oakley, K. (2011) 'In its own image: New Labour and the cultural workforce'. Cultural Trends, 20 (3-4), 281-9. https://doi.org/10.1080/09548963.2011.589709.

Oakley, K. (2013) 'Making workers: Higher education and the cultural industries workplace'. In D. Ashton and C. Noonan (eds), Cultural Work and Higher Education. London: Palgrave Macmillan. $25-44$.

OECD (Organisation for Economic Co-operation and Development) (1996) The KnowledgeBased Economy. Paris: OECD. Accessed 21 June 2021. https://basicknowledge101.com/pdf/ KNOWLEDGE-BASED\%20ECONOMY.pdf.

Osborne, T. (2003) 'Against "creativity": A philistine rant'. Economy and Society, 32 (4), 507-25. https://doi.org/10.1080/0308514032000141684

Osborne, T. (2004) 'On mediators: Intellectuals and the ideas trade in the knowledge society'. Economy and Society, 33 (4), 279-306. https://doi.org/10.1080/0308514042000285224.

Ozga, J. and Jones, R. (2006) 'Travelling and embedded policy: The case of knowledge transfer'. Journal of Education Policy, 21 (1), 1-17. https://doi.org/10.1080/02680930500391462.

Pereira, M. do Mar. (2016) 'Struggling within and beyond the Performative University: Articulating activism and work in an "academia without walls"'. Women's Studies International Forum, 54, 100-10. https://doi.org/10.1016/j.wsif.2015.06.008.

Pratt, A.C. (2005) 'Cultural industries and public policy: An oxymoron?'. International Journal of Cultural Policy, 11 (1), 31-44. https://doi.org/10.1080/10286630500067739.

Prince, R. (2010) 'Policy transfer as policy assemblage: Making policy for the creative industries in New Zealand'. Environment and Planning A, 42 (1), 169-86. https://doi.org/10.1068/a4224.

Prince, R. (2013) 'Calculative cultural expertise? Consultants and politics in the UK cultural sector'. Sociology, 48 (4), 747-62. https://doi.org/10.1177/0038038513502132.

Prince, R. (2017) 'Local or global policy? Thinking about policy mobility with assemblage and topology'. Area, 49 (3), 335-41. https://doi.org/10.1111/area.12319.

Rindzevičiūtè, E., Svensson, J. and Tomson, K. (2016) 'The international transfer of creative industries as a policy idea'. International Journal of Cultural Policy, 22 (4), 594-610. https://doi.org/10.1080/ 10286632.2015.1025067. 
Rose, N. (1999) Powers of Freedom: Reframing political thought. Cambridge: Cambridge University Press.

Rose, N., O'Malley, P. and Valverde, M. (2006) 'Governmentality'. Annual Review of Social Sciences, 2, 83-104. https://doi.org/10.1146/annurev.lawsocsci.2.081805.105900.

Rose-Redwood, R.S. (2006) 'Governmentality, geography and the geo-coded world'. Progress in Human Geography, 30 (4), 469-86. https://doi.org/10.1191/0309132506ph619oa.

Rose-Redwood, R.S. (2008) 'Indexing the great ledger of the community: Urban house numbering, city directories, and the production of spatial legibility'. Journal of Historical Geography, 34 (2), 286-310. https://doi.org/10.1016/j.jhg.2007.06.003.

Schlesinger, P. (2017) 'The creative economy: Invention of a global orthodoxy'. Innovation: The European Journal of Social Science Research, 30 (1), 73-90. https://doi.org/10.1080/13511610.2016. 1201651.

Senellart, M. (2007) 'Course context'. In M. Senellart (ed.), Security, Territory, Population: Lectures at the College de France 1977-1978. London: Palgrave Macmillan, 369-403.

Shore, C. and McLauchlan, L. (2012) "'Third mission" activities, commercialisation and academic entrepreneurs'. Social Anthropology, 20 (3), 267-86. https://doi.org/10.1111/j.1469-8676.2012.00207.x.

Simons, M., Olssen, M. and Peters, M.A. (2009) Re-Reading Education Policies: A handbook studying the policy agenda of the 21st century. Rotterdam: Sense Publishers.

Stone, D. (2017) 'Understanding the transfer of policy failure: Bricolage, experimentalism and translation'. Policy and Politics, 45 (1), 55-70. https://doi.org/10.1332/03055731 6X14748914098041.

Thrift, N. (2006) 'Re-inventing invention: New tendencies on capitalist commodification'. Economy and Society, 35 (2), 279-306. https://doi.org/10.1080/03085140600635755.

Tyndall, K. (2007) The Producers: Alchemists of the impossible. London: The Jerwood Charitable Foundation.

UUK (Universities UK) (2010) Creating Prosperity: The role of higher education in driving the UK's creative economy. Accessed 13 June 2021. https://www.universitiesuk.ac.uk/policy-and-analysis/ reports/Documents/2010/creating-prosperity-the-role-of-higher-education.pdf.

Virani, T. and Pratt, A.C. (2016) 'Intermediaries and the knowledge exchange process: The case of the creative industries and higher education'. In R. Comunian and A. Gilmore (eds), Higher Education and the Creative Economy: Beyond the campus. London: Routledge.

Vostal, F. and Robertson, S. (2012) 'Knowledge mediators and lubricating channels: On the temporal politics of remissioning the university'. TOPIA: Canadian Journal of Cultural Studies, 28, 143-64. https://doi.org/10.3138/topia.28.143.

Williams, A., Dovey, J., Cronin, B., Garside, P., Flintham, M., Smith, M., Barrett, D., Brooks, R., Boddington, A. and Taylor, F. (2018) Hidden Story: Understanding knowledge exchange partnerships with the creative economy. London: University Alliance.

Wilson, N. (2010) 'Social creativity: Re-qualifying the creative economy'. International Journal of Cultural Policy, 16 (3), 367-81. https://doi.org/10.1080/10286630903111621.

Work Foundation (2007) Staying Ahead: The economic performance of the UK's creative industries. Accessed 20 June 2021. www.a-n.co.uk/research/staying-ahead-the-economic-performance-ofthe-uks-creative-industries-3/.

Wright, S. and Shore, C. (eds) (2017) Death of the Public University?: Uncertain futures for higher education in the knowledge economy. New York: Berghahn. 